\title{
Editorial
}

\section{Nanomaterials in Photo (Electro) Catalysis}

\author{
Francesca Petronella $1, *(\mathbb{1})$ and Roberto Comparelli $2, *$ (i) \\ 1 CNR-IC, Istituto di Cristallografia, S.S. Montelibretti, Via Salaria Km 29,300, 00015 Rome, Italy \\ 2 CNR-IPCF, Istituto per i Processi Chimico Fisici, S.S. Bari, c/o Dip. Chimica Via Orabona 4, 70126 Bari, Italy \\ * Correspondence: francesca.petronella@cnr.it (F.P.); roberto.comparelli@cnr.it (R.C.)
}

Citation: Petronella, F.; Comparelli, R. Nanomaterials in Photo (Electro) Catalysis. Catalysts 2021, 11, 149. https://doi.org/10.3390/catal11020149

Received: 15 January 2021

Accepted: 19 January 2021

Published: 21 January 2021

Publisher's Note: MDPI stays neutral with regard to jurisdictional claims in published maps and institutional affiliations.

Copyright: (c) 2021 by the authors. Licensee MDPI, Basel, Switzerland. This article is an open access article distributed under the terms and conditions of the Creative Commons Attribution (CC BY) license (https:// creativecommons.org/licenses/by/ $4.0 /)$.

\section{Introduction}

The increasing rate of water and air pollution dramatically impacts natural ecosystems and human health causing depletion of biodiversity, climate changes, spreading of respiratory diseases, and, as a consequence, negatively impacting the world economy [1] Therefore, the need for innovative and sustainable pollution control and clean energy production systems is urgent.

However, most of the available water treatment technologies merely concentrate the pollutants by transferring them to other phases that still need further treatments, thus not completely "eliminating" or "destroying" the contaminants [2], or involve high operating costs and could generate toxic secondary pollutants into the ecosystem [3].

Conversely, new strategies based on advanced oxidation processes (AOP) show the potential to completely mineralize the target pollutant leading to harmless molecules, through the in situ generation of Reactive Oxygen Species (ROS; i.e., $\mathrm{H}_{2} \mathrm{O}_{2}, \mathrm{OH}^{-}, \mathrm{O}_{2}{ }^{-}$, $\mathrm{O}_{3}$ ) under mild conditions [4]. Among the AOP processes, semiconductor assisted photocatalysis has attracted a lot of attention because it is essentially a cost-effective process that could take place at both solid/air and solid/liquid interface. Its successful application has been demonstrated in several fields such as air and water remediation, microbial inactivation, and cultural heritage protection $[5,6]$. The generation of ROS in semiconductor assisted photocatalytic process, occurs upon the photoexcitation of the semiconductor (e.g., $\mathrm{TiO}_{2}$ or $\mathrm{ZnO}$ ) that promotes the generation of photoelectrons in the conduction band and photoholes in the valence band. The combination of photocatalysis and electrochemical technologies gives rise to the photoelectrocatalysis (PEC), considered as an effective technique for pollutant mineralization in water. Indeed, PEC avoids electron and hole recombination events (that strongly limit the photocatalysis efficiency) by applying an external bias on a photoanode such as a $\mathrm{TiO}_{2}$-based substrate. When the photoanode is irradiated, the applied bias promotes the transfer of the photogenerated electrons from the anode to the cathode through an external circuit [7].

Photogenerated electrons and holes, reacting with water molecules and/or oxygen molecules absorbed on the semiconductor surface, generate ROS, triggering a sequence of oxidation reactions able to degrade and potentially mineralize target pollutants.

The present special issue aims at providing an updated and original collection of recent advances in the field of synthesis and characterization of photoactive nanomaterials, designed for environmental applications that include (but are not limited to) the degradation of pollutants, the conversion and production assisted by $\mathrm{UV}$, visible, or solar light.

\section{This Special Issue}

This special issue collects one review, and ten research articles that critically focus on cutting-edge nanomaterials, designed for photocatalysis and photoelectrocatalysis.

The article from Cao et al. deals with the preparation and characterization of fabrics, coated with commercial $\mathrm{TiO}_{2} \mathrm{P}_{25}$ nanoparticles modified and doped by chloride ions which provide a negative surface charge to promote the adsorption of cationic dyes and 
induce oxygen vacancies that modify the $\mathrm{TiO}_{2}$ energy gap ultimately enhancing visible light absorption as demonstrated by the degradation of Methyl Orange, Methylene Blue, and Rhodamine B [8].

The preparation of efficient $\mathrm{TiO}_{2}$ based nanosized photocatalyst in simple and mild conditions, is one of the hot topics of the present special issue. Such a subject, indeed, is closely related to the application on large scale of $\mathrm{TiO}_{2}$ assisted photocatalysis. Indeed, Dell'Edera et al. report the synthesis of mesoporous $\mathrm{TiO}_{2}$ anatase nanostructures by a lowcost and environmentally sustainable route suitable to yield up to $40 \mathrm{~g}$ of product per batch. The proposed approach exploits $\mathrm{TiOSO}_{4}$ alkaline hydrolysis at room temperature followed by mild thermal treatment of the collected powder. The photocatalytic performances, investigated in the degradation of Methylene Blue, show a progressive increase as a function of the thermal treatment time [9].

The preparation of an efficient visible light active photocatalyst with reduced costs is also the objective of the work by Cizmar et al., who investigates several approaches for the synthesis of $\mathrm{Cu}$-modified nanoporous $\mathrm{TiO}_{2}$. The authors examined several synthetic routes, including the hydrothermal synthesis, the anodization with $\mathrm{Cu}$ source, the electrodeposition, and the spin-coating, using two different copper sources. The photocatalysts characterization performed by X-ray Diffraction, Raman Spectroscopy, Scanning Electron Microscopy, and Energy Dispersive X-ray spectroscopy and the investigation on the photocatalytic activity, allows to establish a correlation among the synthesis path, the $\mathrm{Cu}$ concentration, and the photocatalytic activity. The overall results point out that spin-coating is faster, cheaper, and more suitable for scale-up synthesis of the investigated photocatalyst [10].

The large scale application of photocatalysis requires photocatalyst stability and recyclability. Such an issue is critically addressed in the paper published by Wint et al. that investigates the recyclability $\mathrm{TiO}_{2}$ nanotubes $\left(\mathrm{TiO}_{2} \mathrm{NTs}\right)$ and $\mathrm{TiO}_{2} \mathrm{NTs}$ decorated with $\mathrm{Ag}$ nanoparticles $\left(\mathrm{TiO}_{2} \mathrm{NTs} / \mathrm{Ag}\right)$ prepared by electrochemical anodization. The two photocatalysts, characterized by FESEM, XRD, reflectance spectroscopy, XPS analysis, are tested in the photodegradation of Methylene Blue under UV light irradiation, that demonstrates the increases of the reaction rate, promoted by the presence of Ag nanoparticles [11].

The paper from Khezrianjoo et al. investigates the photocatalytic degradation of a food dye, assisted by commercially available $\mathrm{TiO}_{2}$ and $\mathrm{ZnO}$ nanoparticles, respectively. The target food dye is the Food Black 1 that has harmful effects on cells even at low concentrations. This paper examines several photocatalysis parameters including decolorization, dearomatization, and mineralization. Important, authors also perform a toxicological investigation by analyzing seed germination and root growth of the Lepidium sativum $\mathrm{L}$. (L. sativum L.) in the water solutions treated by photocatalysis [12].

Scientists are extremely active in the investigation of novel photocatalysts based on $\mathrm{ZnO}$ or $\mathrm{TiO}_{2}$ modified with carbon-based nanostructures to improve the photocatalytic performance of plain semiconductors. In this regard, the paper by Ramos et al. describes the synthesis of zinc oxide-reduced graphene oxide (ZnO-rGO) nanorods (NRs) by a hydrothermal route, using electrospun $\mathrm{ZnO}$-rGO seed layers. The $\mathrm{ZnO}-\mathrm{rGO}$ seed layer is realized on an FTO substrate by electrospinning, exploring several experimental conditions. As a result, the photocatalytic activity of the ZnO-rGO NRs is related to the applied spinning voltage value that affects morphological, structural, and optical properties of the resulting ZnO-rGO NRs [13].

Plasmonic photocatalysts can represent a valuable alternative to $\mathrm{TiO}_{2}$ and $\mathrm{ZnO}$ nanoparticles for photocatalytic processes under visible light irradiation, as demonstrated by two papers of the present special issue.

A series of $\mathrm{Ag} / \mathrm{Pd} / \mathrm{m}-\mathrm{BiVO}_{4}$ (monoclinic) bimetallic nano-microspheres with photocatalytic properties are reported in the paper of Yu et al. The photocatalysts, prepared by a two-step method (hydrothermal synthesis and chemical reduction) have been characterized by several techniques, and their photocatalytic activity has been investigated in the oxidation of benzyl alcohol under visible light irradiation, in several organic solvents. Optimal 
conditions for the preparation of the nano-microspheres allow to produce a photocatalyst able to achieve a conversion rate up to $89.9 \%$ and a selectivity greater than $99 \%$ under suitable experimental conditions [14].

The paper of Ryu et al. deals with the preparation, characterization, and testing of a plasmonic photocatalyst consisting of $\mathrm{AgCl}$ nanostructures decorated with bimetallic moieties of $\mathrm{Ag}$ and $\mathrm{Au}$ (AgCl@AgAu NPs). The paper explores several preparation conditions, focusing on the effect of the molecular weight of the polyvinylpyrrolidone that affects the shape of the resulting nanostructure. Experimental results from the paper of Ryu et al. describe a valuable approach to control the reduction of metal ions, thus controlling the plasmonic properties of the nanostructure. Further, the correlation between the structural, compositional, and photocatalytic properties of $\mathrm{AgCl}$-based nanomaterials is demonstrated [15].

The present special issue also includes two papers focused on nanomaterials for PEC. The work from the group of Mascolo et al. investigates the removal of carbamazepine by PEC and conventional photocatalysis. In this paper, the photocatalyst is prepared by Plasma Electrolytic Oxidation from a titanium expanded mesh, resulting in a $\mathrm{TiO}_{2}$ mesh with a porous morphology. The photocatalytic investigation considers several AOP methods such as: $\mathrm{PEC}, \mathrm{TiO}_{2}$ assisted photocatalysis, electrochemical oxidation, $\mathrm{TiO}_{2} \mathrm{P} 25$ assisted photocatalysis, and direct photolysis. Identification of the transformation products and possible degradation pathways of carbamazepine are also reported, pointing out the generation of secondary products with low molecular weight, thus assessing the efficiency of the process. The results highlight the efficiency of the PEC that promotes $99 \%$ of carbamazepine removal in less than one hour of reaction [16].

A further paper dealing with PEC is published by Franz et al. This work reports the preparation and characterization of $\mathrm{TiO}_{2}$ films, by Plasma Electrolytic Oxidation in different experimental conditions, controlling the crystalline composition of $\mathrm{TiO}_{2}$ particles. This study reports not only the photoelectrocatalytic activity of the obtained $\mathrm{TiO}_{2}$ films, but also the photoelectrochemical activity, assessed by measuring incident photon-tocurrent efficiency (IPCE) under UV light irradiation. Experimental results point out that films with higher IPCE values are the most efficient photocatalysts under the investigated experimental conditions [17].

Finally, the review article by Sakdaronnarong et al. reports on the new opportunities arising from the use of carbon dots (CDs) for photocatalysis-related applications. Although CDs are not itself photocatalysts, they can enhance the photocatalytic activity because of two mechanisms. Indeed, upon photoexcitation of CDs with long-wavelength visible light, they can emit photons with higher energies to photoexcite photocatalytic semiconductors. Second, in combination with photocatalytic semiconductors, CDs with a proper band gap can promote the separation of charges, enhances charge migration efficiency, thus increasing the number of charge carriers that are available for photocatalytic reactions. The review outlines synthesis approaches for the preparation of CDs, modification of photocatalysts with CDs, and applications in several fields, including water treatment and hydrogen production. A further section is devoted to enzyme-mimetic and photodynamic applications [18].

In conclusion: this special issue is an optimal reference point for researchers investigating new approaches for the synthesis of nanomaterials purposely designed for the real-scale application of photocatalysis and PEC. The published papers not only focus on the synthesis procedures but cover several aspects of the photocatalytic process, including reaction pathways of pollutants, recyclability and eco-toxicology.

Acknowledgments: We would like to thank all the authors for their great contributions, and the reviewers for the time they dedicated to reviewing the manuscripts. We would like to acknowledge the staff of the Materials Editorial Office for their great support during the preparation of this Special Issue.

Conflicts of Interest: The authors declare no conflict of interest. 


\section{References}

1. Campbell-Lendrum, D.; Prüss-Ustün, A. Climate change, air pollution and noncommunicable diseases. Bull. World Health Organ. 2019, 97, 160-161. [CrossRef] [PubMed]

2. Chong, M.N.; Jin, B.; Chow, C.W.K.; Saint, C. Recent developments in photocatalytic water treatment technology: A review. Water Res. 2010, 44, 2997-3027. [CrossRef] [PubMed]

3. Gaya, U.I.; Abdullah, A.H. Heterogeneous photocatalytic degradation of organic contaminants over titanium dioxide: A review of fundamentals, progress and problems. J. Photochem. Photobiol. C Photochem. Rev. 2008, 9, 277-287. [CrossRef]

4. Mousset, E.; Dionysiou, D.D. Photoelectrochemical reactors for treatment of water and wastewater: A review. Environ. Chem. Lett. 2020, 18, 1301-1318. [CrossRef]

5. Petronella, F.; Truppi, A.; Dell'Edera, M.; Agostiano, A.; Curri, M.L.; Comparelli, R. Scalable Synthesis of $\mathrm{Mesoporous} \mathrm{TiO}_{2}$ for Environmental Photocatalytic Applications. Materials 2019, 12, 1853. [CrossRef] [PubMed]

6. De Pasquale, I.; Lo Porto, C.; Dell'Edera, M.; Petronella, F.; Agostiano, A.; Curri, M.L.; Comparelli, R. Photocatalytic TiO 2 -Based Nanostructured Materials for Microbial Inactivation. Catalysts 2020, 10, 1382. [CrossRef]

7. Ye, S.; Chen, Y.; Yao, X.; Zhang, J. Simultaneous removal of organic pollutants and heavy metals in wastewater by photoelectrocatalysis: A review. Chemosphere 2020, 2020, 128503. [CrossRef]

8. Cao, Z.; Zhang, T.; Ren, P.; Cao, D.; Lin, Y.; Wang, L.; Zhang, B.; Xiang, X. Doping of Chlorine from a Neoprene Adhesive Enhances Degradation Efficiency of Dyes by Structured $\mathrm{TiO}_{2}$-Coated Photocatalytic Fabrics. Catalysts 2020, 10, 69. [CrossRef]

9. Dell’Edera, M.; Petronella, F.; Truppi, A.; Liotta, L.F.; Galli, N.; Sibillano, T.; Giannini, C.; Brescia, R.; Milano, F.; Striccoli, M.; et al. Low Temperature Synthesis of Photocatalytic Mesoporous $\mathrm{TiO}_{2}$ Nanomaterials. Catalysts 2020, 10, 893. [CrossRef]

10. Čižmar, T.; Panžić, I.; Salamon, K.; Grčić, I.; Radetić, L.; Marčec, J.; Gajović, A. Low-Cost Synthesis of Cu-Modified Immobilized Nanoporous $\mathrm{TiO}_{2}$ for Photocatalytic Degradation of $1 \mathrm{H}$-Benzotriazole. Catalysts 2020, 10, 19. [CrossRef]

11. Wint, T.H.M.; Smith, M.F.; Chanlek, N.; Chen, F.; Oo, T.Z.; Songsiriritthigul, P. Physical Origin of Diminishing Photocatalytic Efficiency for Recycled $\mathrm{TiO}_{2}$ Nanotubes and Ag-Loaded $\mathrm{TiO}_{2}$ Nanotubes in Organic Aqueous Solution. Catalysts 2020, $10,737$. [CrossRef]

12. Khezrianjoo, S.; Lee, J.; Kim, K.-H.; Kumar, V. Eco-Toxicological and Kinetic Evaluation of $\mathrm{TiO}_{2}$ and ZnO Nanophotocatalysts in Degradation of Organic Dye. Catalysts 2019, 9, 871. [CrossRef]

13. Ramos, P.G.; Luyo, C.; Sánchez, L.A.; Gomez, E.D.; Rodriguez, J.M. The Spinning Voltage Influence on the Growth of ZnO-rGO Nanorods for Photocatalytic Degradation of Methyl Orange Dye. Catalysts 2020, 10, 660. [CrossRef]

14. Yu, X.; Li, H.; Hao, X.; Zhang, Z.; Wang, Y.; Li, J.; Wang, K. Selective Oxidation of Benzyl Alcohol by Ag/Pd/m-BiVO4 Microspheres under Visible Light Irradiation. Catalysts 2020, 10, 266. [CrossRef]

15. Ryu, H.-J.; Kim, H.-L.; Joo, J.H.; Lee, J.-S. Structurally and Compositionally Tunable Absorption Properties of AgCl@AgAu Nanocatalysts for Plasmonic Photocatalytic Degradation of Environmental Pollutants. Catalysts 2020, 10, 405. [CrossRef]

16. Franz, S.; Falletta, E.; Arab, H.; Murgolo, S.; Bestetti, M.; Mascolo, G. Degradation of Carbamazepine by Photo(electro)catalysis on Nanostructured $\mathrm{TiO}_{2}$ Meshes: Transformation Products and Reaction Pathways. Catalysts 2020, 10, 169. [CrossRef]

17. Franz, S.; Arab, H.; Lucotti, A.; Castiglioni, C.; Vicenzo, A.; Morini, F.; Bestetti, M. Exploiting Direct Current Plasma Electrolytic Oxidation to Boost Photoelectrocatalysis. Catalysts 2020, 10, 325. [CrossRef]

18. Sakdaronnarong, C.; Sangjan, A.; Boonsith, S.; Kim, D.C.; Shin, H.S. Recent Developments in Synthesis and Photocatalytic Applications of Carbon Dots. Catalysts 2020, 10, 320. [CrossRef] 